\title{
The Role of Imaging in Proof of Concept for CNS Drug Discovery and Development
}

\author{
Dean F Wong ${ }^{\star, 1}$, Johannes Tauscher ${ }^{2}$ and Gerhard Gründer ${ }^{3}$ \\ ${ }^{1}$ Departments of Radiology, Psychiatry, Neuroscience and Environmental Health Sciences, Johns Hopkins University School \\ of Medicine and Bloomberg School of Public Health, Johns Hopkins University, Baltimore, MD, USA; ${ }^{2}$ Lilly Research Labs, \\ Eli Lilly \& Co., Indianapolis, IN, USA; ${ }^{3}$ Department of Psychiatry and Psychotherapy, RWTH Aachen University, Aachen, \\ Germany
}

Neuroimaging, particularly that of neuroreceptor radioisotope and functional magnetic resonance imaging (fMRI), has played a fundamental role in neuropharmacology and neurophysiology. Because of the unique and pioneering role, especially of the radiolabeling of central nervous system (CNS) drugs for receptor and neurotransmitter system imaging, there is an increasingly major role to aid in CNS drug development. One component is providing evidence for proof of concept of the target for which candidate drugs are being tested for receptor occupancy mechanism of action and ultimately rational drug dosing. There is also a role for other areas of neuroimaging, including fMRI and magnetic resonance spectroscopy in other magnetic resonance-based techniques that, together with radioisotope imaging, represent 'CNS molecular imaging.' The role of these approaches and a review of the recent advances in such neuroimaging for proof-of-concept studies is the subject for this paper. Moreover, hypothetical examples and possible algorithms for early discovery/phase I development using neuroimaging provide specific working approaches. In summary, this article reviews the vital biomarker approach of neuroimaging in proof of concept studies.

Neuropsychopharmacology Reviews (2009) 34, 187-203; doi: I0. I038/npp.2008. I66; published online 8 October 2008

Keywords: positron emission tomography; magnetic resorance imaging; occupancy; dose finding; proof-of-concept; proof of mechanism

\section{INTRODUCTION}

Imaging biomarkers have an increasingly important function in drug discovery and development as a key bridge between the laboratory and the clinic. Indeed, imaging was highlighted in the FDA's Critical Path Initiative as a key technology to overcome the stagnation in the development and registration of innovative medicines. When used appropriately, imaging is anticipated to drive the selection and validation of drug molecules, targets, and therapeutic hypotheses thereby increasing the probability of success of drug development programs (DouglasThrockmorton, MD, acting deputy director, CDER, FDA, 23 September, 2005, FDA Critical Path Initiative-Opportunities and Challenges Presentation, cv2005throckmortonfda-pom-pdf; George Mills, director of the Division of Medical Imaging and Radiopharmaceutical Products Regulatory Opportunities and Challenges of Imaging As A Drug

${ }^{*}$ Correspondence: Dr DF Wong, Johns Hopkins University School of Medicine, Johns Hopkins University School of Medicine, 601 North Caroline St, JHOC Room 3245, Baltimore, MD, 21287-0807, USA, Tel: +1410 955 8433, Fax: +1 410955 0696, E-mail: dfwong@jhmi.edu Received 21 April 2008; revised 15 August 2008; accepted 17 August 2008
Development Tool, May, 2005 www.fda.gov/cder/regulatory/ medImaging/imagingKeyNote.ppt).

Clinical evaluation of new drug candidates can be accelerated through the integration of imaging into early assessment paradigms in humans. Development of these imaging techniques and technologies may begin in preclinical models and support two critical phases of drug discovery and development: (1) early clinical experiments that are designed to demonstrate 'proof of biology' by testing a novel hypothesis that link target engagement (TE) to drug-induced biological changes expected to give clinical benefit; and (2) subsequent clinical experiments that demonstrate proof of concept $(\mathrm{PoC})$, ie engaging a particular target is linked to a meaningful change in a clinical end point thus demonstrating a new avenue to treat a condition in patients. Translational imaging has been particularly valuable in the neurosciences where, due to the inaccessibility of the human brain, the use of radioisotopes (PET and SPECT) and magnetic resonance imaging (MRI) is central to the assessment of brain penetration, neurotarget engagement, brain function, and neuropathology.

In this review, we aim to clarify through the use of specific examples where imaging biomarkers have proven to be useful in central nervous system (CNS) drug discovery 
and development. We will consider radioisotope imaging, and functional and structural MRI tools and technologies, most of which can be used in micro- and macro-imaging formats allowing hypothesis generation and testing in small animals, nonhuman primates, healthy human volunteers, and patients.

Radiolabeling of drugs and molecular imaging agents with positron-emitting $\left({ }^{11} \mathrm{C}\right.$ or $\left.{ }^{11} \mathrm{~F}\right)$ radionuclides is the most commonly used technique to assess the brain penetration of candidate drugs, map neurotransmitter receptor or transporter populations in health and disease, and measure engagement of putative therapeutic targets by potential drug candidates. Importantly, for CNS drug development, establishing the relationship between drug exposure (dose or plasma concentration) and TE enables appropriate dose selection for early clinical trials and thereby accelerates phase IIB of clinical development. PET and SPECT imaging can also be used to evaluate the molecular pathology of CNS diseases. Examples of this are the specific radioligands that have been developed to identify inflammatory responses in multiple sclerosis (MS) and the deposition of amyloid within the brain in Alzheimer's disease (AD). Molecular imaging agents that identify specific CNS disorders have great value for staging disease and the stratification of patients for inclusion in clinical trials. Clearly, in the early stages of hypothesis testing, it is very important to include those patients with the highest likelihood of response to intervention in the mechanism being studied. An example here would be high amyloid burden for $\mathrm{AD}$ to test modifying therapies targeted at this hypothesized component of the disease.

Specifically, we will discuss how imaging biomarkers can facilitate the development of novel CNS drugs either using established or newly developed PET radiotracers for a particular target (eg various dopamine (DA) or serotonin receptors and transporters), or where they have been used to study what degree of TE is needed to exert positive clinically therapeutic effects (eg NET occupancy in ADHD; or CB1 occupancy in obesity and other psychiatric disorders; or even an enzyme effect such as in the second messenger systems as PDE I-V). Unlike neutral orthosteric site antagonists, there are considerable challenges associated with assessment of the TE of agonists, partial agonists, inverse agonists, and allosteric modulators and how to link this TE to efficacy. This is of particular interest as for example many of the new therapeutic approaches to psychiatric disorders use positive allosteric modulators as a means to fine-tune the primary excitatory and inhibitory neurotransmitter (glutamate and GABAergic) systems within the brain.

In contrast to the study of distinct receptor populations with PET, functional magnetic resonance imaging (fMRI) and arterial spin labeling (ASL) have been used in normal healthy volunteers and patient populations to study the brain systems responses to external stimuli and the modification of these responses by drug treatment. fMRI and ASL give complementary information to neuroreceptor imaging by revealing the neurocircuitry involved in behavior and responses. The maturity of fMRI and ASL in drug discovery and development is at an earlier stage than radioisotope imaging but there are emerging examples of its value in the study of depression and antidepressants, pain and analgesics, cognition, aging, and substance/alcohol abuse (Borsook et al, 2006; Hargreaves, 2008; Wise and Tracey, 2006). Structural MRI (gadolinium-enhanced visualization of white matter lesions) has been used in the study of MS and was central to drug registration for the treatment of this disorder ( $\mathrm{Lu}$ et al, 2006; Hermann et al, 2008). Interestingly, however, it has been subsequently determined that the imaging measure may be more sensitive than symptoms thereby altering its use in the drug discovery paradigm. Thus, if no resolution of the lesion is seen, the therapy is probably going to be unsuccessful; but if resolution is observed, then dosing should be continued to give the best chance to see maximum therapeutic benefit. Structural imaging (volumetric MRI) is central to the assessment of stroke and neurodegeneration and may provide a key surrogate outcome measure for the evaluation of disease modifying therapies in AD. Defining the rate of progression of brain atrophy and CNS amyloid burden alongside neuropsychiatric scores in Alzheimer's patients under usual care today is the goal of Alzheimer's Disease Neuroimaging Initiatives (ADNI, 2008) in the United States, Japan, Europe, and Australia.

\section{PROOF OF CONCEPT AND IMAGING}

In CNS research, the field most active in the use of imaging in drug development, the terms 'proof of concept' (PoC), 'proof of principle', or 'proof of mechanism' (PoM) are frequently used. We propose to focus on PoC. As outlined above, PoC in the context of drug development means that a phase II clinical trial demonstrated that engaging a target was linked to a clinical end point demonstrating a new avenue to treat a condition in patients. We will consider PoC as being target specific rather than compound/drug specific, although this leaves the important question unanswered whether the rejection of PoC for one drug (despite high TE) disqualifies all drugs binding to this same target from further clinical evaluation. For the drug candidate itself, we will refer to it as proof of drug candidate (PoDC).

An example using this term is to describe the first clinical evidence derived from a sometimes relatively small phase II clinical trial that confirms preclinical data demonstrating a novel mechanism may be a viable treatment for a human disease.

In essence, the goals of PoC are consistent with the FDA's Critical Path Initiative. As outlined on the FDA's website (http://www.fda.gov/oc/initiatives/criticalpath/), the Critical Path Initiative is FDA's effort to stimulate and facilitate a national effort to modernize the scientific process through which a potential human drug, biological product, or medical device is transformed from a discovery or PoC 
into a medical product. In CNS drug development, those goals may include early indicators as to whether the lead drug candidate for future clinical development crosses the blood-brain barrier (BBB), thus delivered to the target compartment (ie the brain), and engages the appropriate target (eg receptor, transporter, enzyme, or other neurotransmitter system changes) in a dose/exposure-related manner. If there is preclinical data indicating that a certain degree of TE, eg receptor occupancy (RO), is necessary to demonstrate activity in a relevant animal model, then the subsequent determination of human TE can be used to guide dosing in the human $\mathrm{PoC}$, the phase II clinical trial. However, as stated above, the level of TE needed for a therapeutic effect might markedly differ between agonists, partial agonists, and antagonists.

If the $\mathrm{PoC}$ is positive, providing 'evidence' that a novel target shows promise to treat a disease in humans, the advantage of using imaging for rational dose finding is that it limits the doses brought forward into clinical trials, thus preventing unnecessary exposures to doses much too high or too low. Conversely, if a dose that demonstrated adequate TE in humans did not lead to signs of clinical efficacy in the clinical trial, the PoC can be rejected, and a drug target can be abandoned more quickly and with more confidence that an adequate dose of the particular compound tested was used to provide a valid test of the mechanism. To achieve this, however, would require a high level of confidence that adequate TE had been achieved. The level of TE might be inferred from results of several different types of imaging studies, eg (1) using isotopically labeled drug candidates (generally using either C-11 or F-18 tracers) to estimate total brain exposure, (2) functional studies such as measurement of test drug effects on regional cerebral blood flow (PET/SPECT or MRI), or (3) a direct measure of TE employing a PET radioligand that can be used for measuring occupancy; for example $\mathrm{DA}_{2} / \mathrm{D}_{3} \mathrm{RO}$ studies with $\left[{ }^{11} \mathrm{C}\right]$ raclopride. It is challenging to determine what level of TE is needed for a novel mechanism for a class of compounds, and this would typically be guided by efficacy studies in appropriate preclinical models.

\section{STATEMENT OF PROBLEM}

It has generally been observed that more of CNS drug development is mechanism dependent and requires PoM to efficiently and economically move potential therapeutic candidates either with or without the identified target from preclinical to early clinical studies. In the early phases, this begins with CNS drugs that are typically characterized in increasingly complex animal models, including knockout mice and nonhuman primates. Here PET, SPECT, and MR are actively used in preclinical models in vivo (eg Maeda et al, 2007). When there is a series of drug candidates, however, initial evaluations about which candidates should undergo toxicology or further development with increasingly sophisticated in vitro or in vivo methods for metabolism and toxicity studies, it may be possible to have a series of compounds available as potential clinical candidates. Decisions then have to be made about which compounds to test to eventually establish the appropriate regulatory and final safety data required by regulatory bodies such as the FDA or the European Medicines Agency. Thus, the decision as to which compounds to evaluate at this next expensive and time-consuming step requires establishment of a number of criteria (see below). Among these include evidence that a certain compound or class of compounds are efficacious in humans or at least enter the target area with the opportunity of carrying out future efficacy studies based on the hypothesized pharmacological and biological mechanisms of action. Actually, in vitro and in vivo animal models - although increasingly sophisticated-still suffer in that they are not human based, where human metabolism, genotype, biodistribution, blood-brain penetration, etc and thus species differences can confound the most carefully planned preclinical approach. A potential way of addressing this is to use a relatively noninvasive methodology such as neuroimaging to establish the PoC for the target. Indeed, use of this methodology, has been growing since the mid 1980s with the advent of human CNS neuroreceptor imaging. Also, as a result of its success for drug development it has proven to be a spearhead for the use of imaging in other therapeutic areas beyond the CNS (such as oncology, cardiology, and orthopedics/rheumatology).

\section{Definitions of Imaging Biomarkers}

To integrate the role of imaging for $\mathrm{PoC}$, its context relative to terms as 'biomarkers and surrogate markers' is relevant and thus this section will review some widely accepted definitions for the term 'biomarker'. Perhaps a useful definition documented by Frank and Hargreaves (2003) is 'a characteristic that is objectively measured and evaluated as an indicator of normal biologic processes, pathogenic processes, or pharmacological responses to a therapeutic intervention'. Ultimately, the efficacy of a drug candidate is measured by a clinical end point. Ideally, a biomarker could serve as a substitute for this clinical outcome providing evidence to predict clinical benefit, efficacy, and side effects. The first step in the drug development process is often PoC that either a drug would fit a class of mechanism of actions known to be therapeutically efficacious, alternatively to directly examine the $\mathrm{PoC}$ that a drug candidate might have some ultimate clinical benefit or clinical efficacy. Using $\mathrm{D}_{2}$ receptor PET imaging as an example, the link between $\mathrm{D}_{2}$ occupancy and efficacy in schizophrenia has helped fortify the PoC for $\mathrm{D}_{2} \mathrm{DA}$ antagonists. This information can now be used to establish a dose range to test for new, pure $\mathrm{D}_{2}$ antagonists. Thus, this might be considered at or 'emerging' biomarker or 'pre-biomarker' it is of considerable value. For the purposes of this article we will use these terms as equivalent. 
The NIH Biomarkers and Surrogate Endpoint Working Group (Atkinson et al, 2001) has defined three levels of biomarkers. These include the biomarkers that track the natural course of disease (type 0), biomarkers that examine effects in intervention along with the known mechanism of action of the drug without strict relationship to clinical outcome (type 1), and biomarkers considered the ultimate 'surrogate end points' as in this type, ideally the change in the biomarker is predictive of clinical outcome (type 2). The efficacy of a specific treatment should be reflected in changes in the biomarker. At present, most imaging methods either do not meet the biomarker status at all, or at best, type 0 or 1 . Such imaging tools for preclinical or early clinical PoC studies will be referred to as 'prebiomarkers' in this article.

\section{EXPLICIT USES OF IMAGING BIOMARKERS FOR PROOF OF CONCEPT}

As noted earlier (Wong et al, 2002), there may be at least four principal roles of imaging in early drug development, especially as pertains to neurotransmitter and neuroreceptor imaging. These include, but are not limited, to (1) justification/rationale for a specific target neurotransmitter system or neurotransmitter receptor system (eg DA and serotonin, etc) as a target for therapeutic intervention; (2) radiolabeling the potential therapeutic compound of interest to examine biodistribution and $\mathrm{BBB}$ penetration of the candidate pharmaceutical; (3) rational therapeutic dosing, which ultimately must be determined to test efficacy efficiently in the target patient population; and (4) mechanism of pharmacological action (ie precisely how it is envisioned that the efficacious action might occur during therapeutic doses in the target patient populations).

\section{FOUR ROLES OF IMAGING IN EARLY DRUG DEVELOPMENT}

\section{Therapeutic Rationale}

Neuroimaging can provide an important role in target identification and therapeutic rationale. A classic example is that the known hyperdopaminergic state associated with positive symptoms of schizophrenia has been characterized to some degree through in vivo imaging. For example, such therapeutic rationale includes evidence from (1) the majority of studies of presynaptic DA neuron function measuring dopa decarboxylase with $\left[{ }^{18} \mathrm{~F}\right]$ fluorodopa; (2) studies demonstrating elevations in amphetamine-induced intrasynaptic DA release (DA occupancy of $\mathrm{D}_{2} / \mathrm{D}_{3}$ receptors by endogenous DA); and (3) a meta-analysis of measurements of $D_{2}$ receptor density or binding potential showing a small but significant elevation, as confirmed later by a number of postmortem studies of schizophrenia. These studies provide lines of evidence reinforcing the DA system's role in psychosis. Furthermore, other evidences from studies in cocaine and alcohol users, as well as methamphetamine and ecstasy users, have demonstrated reductions of DA and some serotonin chemical markers supporting a concept of reduced DA function. Another example is the presumed role of serotonin in affective disorders and obsessive-compulsive disorders (OCDs). A less resolved area is the continued controversy over dopamine transporter (DAT) measurements in ADHD, perhaps reflecting the complexity of this disorder, including the role of norepinephrine as well as DA and perhaps other neurotransmitter systems. Thus, PET and SPECT imaging studies have aided in justifying these therapeutic targets. Perhaps in an ideal situation (but impractical), all disorders could be studied for abnormalities in a neurochemical system or its parameter approaching a biomarker, and if abnormal, this could further point to the justification of carrying out a therapeutic approach. Even so, however, the explicit mechanism of action on that target needs to be demonstrated as described below.

\section{Drug Candidate Biodistribution}

Brief history of human CNS neuroreceptor PET imaging. Traditionally, before the widespread use of neuroimaging, CNS drugs were developed and their biodistribution was primarily tested using ${ }^{3} \mathrm{H}$ - or ${ }^{14} \mathrm{C}$-labeled drugs and examined by methods such as mass spectroscopy or nontracer approaches to determine their ability to penetrate the BBB and potentially reach their targets. Initially, studies measured the drug's receptor affinity (in the case of antipsychotics) or transporter affinity (eg serotonin transporters (SERTs) in the case of some CNS antidepressants, etc), which were first determined by their in vitro properties and then by some in vivo animal models. However, increasingly many CNS drugs were shown to be development failures because of the inability to actually determine if they could enter brain tissue at the appropriate levels in humans. With the widespread use of PET, one subsequent approach was to prepare a radiolabeled version of the drug, ideally isotopically labeled by introducing a radioisotope such as $\left[{ }^{11} \mathrm{C}\right]$ or $\left[{ }^{18} \mathrm{~F}\right]$ where there is no chemical change or minimal change in the drug, to minimize pharmacological changes. One of the first applications of this was the imaging of $\mathrm{D}_{2}$ and $5-\mathrm{HT}_{2 \mathrm{~A}}$ receptors in living human brain using derivatives of the antipsychotic spiperone (also known as spiroperidol). Historically, it was found chemically difficult to radiolabel this drug directly with $\left[{ }^{18} \mathrm{~F}\right]$ even though that would represent an isotopic substitution (and therefore a true representation of the CNS biodistribution of the $\mathrm{D}_{2} / \mathrm{D}_{3}$ DA drug). Hence, through collaborations with investigators in Uppsala University and Johns Hopkins University, a methylated derivative of spiperone, $\left[{ }^{11} \mathrm{C}\right] 3-\mathrm{N}-$ methylspiperone, was developed. This led to successful imaging of $\mathrm{D}_{2} / \mathrm{D}_{3} \mathrm{DA}$ receptors and $5-\mathrm{HT}_{2 \mathrm{~A}}$ receptors, in human brain in May 1983 (Wagner et al, 1983). Shortly after this, other PET centers successfully radiolabeled spiperone and derivative compounds with $\left[{ }^{18} \mathrm{~F}\right]$.

One of the most successful examples and long-lived was the radiolabeling of the antipsychotic raclopride with $\left[{ }^{11} \mathrm{C}\right]$ isotopically. This radiotracer is currently perhaps the most widespread PET ligand in the world. It is noteworthy that 
nonradiolabeled spiperone and raclopride had earlier been studied in the clinic for schizophrenia. Although neither went on to become marketed drugs, their existence allowed pioneering efforts to establish the ability to externally image an antipsychotic drug in living human brain. Before this, such measurements of $D_{2} / D_{3}$ DA receptors were limited to in vitro homogenate studies and later to in vitro and in vivo autoradiographic studies. There was great skepticism in the early 1980s that the ability to image such receptors externally might be challenging, if not impossible. However, a combination of nuclear medicine technology that had already been established (eg imaging the lung through radiolabeled microspheres and the liver through phagocytosis of $\left[{ }^{99 \mathrm{~m}} \mathrm{Tc}\right]$ sulfur colloid) together with the wellestablished CNS neuropsychopharmacology of DA and the quantification of PET led to this successful and rapid development of imaging of neuroreceptors despite the advances of mass spectroscopy and other nontracer screening methods (Need et al, 2007).

Radiolabeling drug candidates: advantages and limitations. Ideally, a new lead drug candidate or a series of drug candidates should be isotopically (ie the same molecule where radiolabeling does not affect the pharmacology) radiolabeled with a PET or SPECT radioisotope as many drugs, depending on their dose level, may be substrates for certain enzyme systems or ligands for receptors/transporters, and thus can be used to determine brain biodistribution. This provides not only a general distribution of the compound, but also some of its washout characteristics. Furthermore, the ability to examine these radiotracers and whether they are substrates for BBB pumps such that multidrug resistance (MDR) would be pertinent not only in human studies but also in animal studies. This is resulting from the increasing understanding that MDR may decrease the observable brain distribution during the imaging time. Thus, as we learn more about the biology of drug distribution, it becomes increasingly important to be able to use radiotracers to track drug kinetics. Options for doing so, unfortunately, are somewhat limited as the primary quantitative radiotracers - including those as the positron emitters of $\left[{ }^{11} \mathrm{C}\right]$, and $\left[{ }^{18} \mathrm{~F}\right]$ or SPECT tracers such as $\left[{ }^{123} \mathrm{I}\right]$ or even less commonly [ ${ }^{99 \mathrm{~m}} \mathrm{Tc}$ ] - label only a very small number of potential drugs (and can decrease lipophilicity), and the radiochemistry is often the most complex technical step in PET/SPECT imaging for drug development.

Other limitations to radiolabeling the drug itself are also evident. Even for compounds that can be isotopically labeled with either ${ }^{11} \mathrm{C}$ or ${ }^{18} \mathrm{~F}$ given the relatively short acquisition times possible with these isotopes $(\sim 90 \mathrm{~min}$ and $\sim 8 \mathrm{~h}$ for ${ }^{11} \mathrm{C}$ and ${ }^{18} \mathrm{~F}$, respectively), these studies may underestimate brain exposure for compounds that cross the BBB slowly and may provide significantly higher brain concentrations after chronic dosing. In addition, these tracer studies provide total brain levels and cannot distinguish between specifically binding to the test drug, tracer free, and tracer nonspecific binding compartments. Furthermore, as imaging cannot distinguish between labeled test drug and brain-penetrated radiolabeled meta- bolites of the test drug, true TE may be overestimated. Conversely, some radiolabeled derivatives of the test drug may provide partial insight if the parent itself cannot be labeled (eg galantamine; Wong et al, 2002), and the derivatives mostly preserve the pharmacology and kinetics of the original.

Therefore, sometimes it may be necessary, as described below, to use existing radiotracers or PET/SPECT tracers that are already able to examine targets in displacement studies that affect/displace these validated radiotracers, specifically binding to determine the drug action or PoC for current therapeutic drugs under study.

Role of MRI in drug distribution. Some MRI methods might also be helpful for determination of drug concentration in animal and human brain. Proton $\left({ }^{1} \mathrm{H}\right)$ spectroscopy (magnetic resonance spectroscopy, MRS) allows for assessment of excitatory (glutamate) and inhibitory ( $\gamma$-amino butyric acid, GABA) amino acids. Both neurotransmitters are important - at least regulatory - in various neuropsychiatric diseases. Several psychotropic drugs, which are widely used in psychiatry, have a GABAergic and/or glutamatergic mechanism of action (eg acamprosate). ${ }^{1} \mathrm{H}$ spectroscopy has been used for determination of both GABA and glutamate. Second, spectroscopy with lithium $\left({ }^{7} \mathrm{Li}\right)$ or fluorine $\left({ }^{19} \mathrm{~F}\right)$ allows for determination of brain concentrations of lithium and some psychotropic drugs containing a fluorine atom. ${ }^{7} \mathrm{Li}$-MRS has been used to quantitate lithium concentrations in patients' brains and to relate it to plasma concentrations (Plenge et al, 1994). ${ }^{19} \mathrm{~F}$ MRS has been used to determine concentrations of fluorinated antipsychotics, such as fluphenazine and trifluoperazine (Durst et al, 1990), and antidepressants such as fluoxetine (Karson et al, 1993). Many other widely used psychotropic drugs such as perphenazine, risperidone, most of the butyrophenone antipsychotics, and the selective serotonin reuptake inhibitors (SSRIs) fluvoxamine and paroxetine contain a fluorine atom. Several benzodiazepines as well as the benzodiazepine antagonist flumazenil are fluorinated.

\section{Rational Drug Dosing Using Imaging as a Tool}

The determination of receptor (or transporter) occupancy is increasingly being used for various classes of psychotropic drugs to guide clinical drug dosing. For the FDA registration of new antipsychotics acting on $\mathrm{D}_{2}$ DA receptors, it is now almost a routine or recommended requirement. Relationships between occupancy of the SERT and other transporter molecules by antidepressants and clinical variables on the other hand are less well established, because only few clinical studies for validation of these markers - with inconclusive results - have been performed. For the antipsychotics, a relatively high RO of their molecular target seems to be a necessity for clinical efficacy, although it is not sufficient for a response in every patient (Wolkin et al, 1989). For the antidepressants, some occupy a comparatively low proportion of their putative target at clinically useful doses, which questions a linear 
relationship between transporter occupancy and clinical efficacy.

By having a portfolio of these radiotracers, it is possible to examine the occupancy of various candidate drugs. Thus, in the area of antipsychotics (and some anxiolytics and antidepressants), this has been relatively successful. The clear drawback is that this approach cannot be used where such radiotracers do not exist. For example, for the recent first phase II clinical trial of the novel $\mathrm{mGluR}_{2 / 3}$ agonist LY404039 in patients with schizophrenia (Patil et al, 2007), a dose had been chosen without the benefit of a PET radiotracer for occupancy studies, because all efforts to develop such a PET ligand failed. Similarly, the failure of L745,870 , a selective $\mathrm{DA} \mathrm{D}_{4}$ receptor antagonist for the treatment of schizophrenia, may have been due to, in part, the absence of a PET marker for occupancy of the target (Kramer et al, 1997). Hence, this role of PET RO is often very relevant.

There remain, however, many issues in using imaging, such as whether a compound is an antagonist, agonist, or a partial agonist; the existence of endogenous neurotransmitter; single- $v s$ multiple-drug dosing; and which brain region is critical for the psychotropic actions of the experimental compound. These are discussed below.

Dopamine antagonists (antipsychotics). The use of DA $\mathrm{D}_{2} / \mathrm{D}_{3}$ receptor imaging during treatment with antipsychotics is historically one of the most commonly used imaging approaches for aiding drug-dosing decisions for later clinical trials. It has been known for more than 30 years that these compounds exert their effects on the positive symptoms of schizophrenia by antagonizing DA $\mathrm{D}_{2}$ receptors (Seeman et al, 1976). It was later discovered with PET that clinically effective doses of typical neuroleptics occupy $\mathrm{D}_{2}$-like DA receptors in the human striatum in the range between 65 and $90 \%$ (Farde et al, 1992). The suggestion of a 'therapeutic window' between 60 and $80 \%$ striatal $\mathrm{D}_{2}$ RO for sufficient treatment response and a 'ceiling' of around $80 \%$ occupancy, above which extrapyramidal side effects (EPS) are likely, was later confirmed by several other researchers (eg Kapur et al, 2000). Although clozapine and quetiapine seem to be exceptions, this rule also applies for most of the second-generation, 'atypical' antipsychotics (Nyberg et al, 1999). When their doses are raised above a certain threshold, striatal (and potentially extrastriatal) $\mathrm{D}_{2}$ DA occupancy increases to levels that are associated with a higher incidence of EPS. As described above the relationship between doses of antipsychotic drugs and their (striatal) $\mathrm{D}_{2}$-like DA RO has almost approached the status of a biomarker, proven to be critical in decisionmaking in the development of new psychotropic drugs (Wong et al, 2002). Although the $\mathrm{D}_{2} / \mathrm{D}_{3}$ occupancy value is clearly related to clinical efficacy and side effects of the class of antipsychotics as a whole, it is not unambiguously correlated with clinical outcome. Schizophrenia is a genetically complex and clinically extremely heterogeneous group of disorders. Positive symptoms such as hallucinations or delusions, which are effectively controlled by antipsychotics in most patients, represent only one- although very important-dimension of phenomenol- ogy. Long-term functional outcome in schizophrenia, however, is determined by improvement in cognitive function rather than control of positive symptoms (Bowie et al, 2006). Because the available antipsychotics have limited activity against cognitive symptoms (Keefe et al, 2007), $D_{2} / D_{3} R O$ is an incomplete marker of disease control or progression.

Although $\mathrm{D}_{2} / \mathrm{D}_{3}$ receptor blockade is relatively well established and suggested by many as a necessary (although not sufficient to 'guarantee' efficacy in all symptom domains of schizophrenia) component of antipsychotic action, there are many factors that could influence the PoC of carrying on a potential drug into future human clinical trials. For CNS drugs in general, this is perhaps the most common in use, exceeding even that of radiolabeling the therapeutic drugs themselves. This is because of the already existing large number of successful radiotracers, such as $\left[{ }^{11} \mathrm{C}\right]$ raclopride or $\left[{ }^{18} \mathrm{~F}\right]$ fallypride for DA imaging or drugs for serotonin receptor or transporter imaging, which have developed after years of primarily radioligand development in academic and, more recently, research imaging centers in the pharmaceutical industry. This rather simplistic receptor model, although applicable and very useful for most antipsychotics, especially when antagonists become more complex for some compounds with extraordinary pharmacological characteristics (as partial agonists), is described later.

Antidepressants and dosing. For the antidepressants, there are important unresolved issues. SSRIs have been shown to occupy $80 \%$ or more of the SERT at clinically used doses (Meyer et al, 2001). Within this class of drugs, this seems to be independent of the specific SSRI. However, the tricyclic antidepressant (TCA) clomipramine has been shown to occupy $80 \%$ of the SERT at doses as low as $10 \mathrm{mg}$, with a calculated median effective dose $\left(\mathrm{ED}_{50}\right)$ of less than $3 \mathrm{mg}$ and a plasma concentration of $1.42 \mathrm{ng} / \mathrm{ml}$ (Suhara et al, 2003). Most surprisingly, the clinically used clomipramine doses are 50-150 mg per day (and even higher doses are used in OCD; Foa et al, 2005). Therapeutic plasma concentrations are in the range of $175-450 \mathrm{ng} / \mathrm{ml}$ (Baumann et al, 2004). These profound discrepancies raise some important questions. First, is blockade of the SERT really the therapeutic principle of clomipramine (and of the TCAs in general)? Or, do TCAs behave completely different from SSRIs, due to their broad pharmacological actions at many different molecular targets? How valid are the studies upon which therapeutic doses and plasma concentrations have been determined for clinical use of the TCAs over decades? On the basis of the two basic assumptions that, first, the SERT (and for some compounds the norepinephrine transporter (NET) is the pharmacological principle through which the SSRIs and clomipramine exert their antidepressant effects, and that, second, the SERT occupancy measured with PET is 'true' occupancy, then generations of patients might have been treated with far too high doses.

The concept is becoming even more complicated if the classes of selective norepinephrine reuptake inhibitors (SNRIs) and dopamine reuptake inhibitors (DRIs) are 
taken into account. Regardless of the type of drug, these compounds seem to occupy the NET and the DAT to a relatively small amount at the doses that are used clinically. If the assumptions are correct that these compounds act by blocking the NET or the DAT and that a relatively high occupancy of the molecular target is needed for efficacy of antagonists, then these antidepressants might be systematically underdosed. Although the SNRI atomoxetine, which is approved for the treatment of ADHD in children, occupies the NET in a dose-dependent manner in monkeys (with relatively high infused doses, with a maximum occupancy of $82 \%$ (Seneca et al, 2006), the occupancy of the NET by single oral atomoxetine doses apparently does not exceed $40 \%$ in humans (Logan et al, 2007). Verification of these results awaits more selective PET radioligands with better reproducibility and accuracy, as these are early generation NET PET ligands that may limit the initial findings.

Even though single-dose studies are not always predictive of the target occupancy found after multiple dosing (discussion follows), studies with similar compounds point in the same direction. The DRI bupropion, administered subchronically to patients with depression, occupies less than $20 \%$ of the DAT at clinical doses (Meyer et al, 2002). The findings with atomoxetine and bupropion raise the question as to whether these compounds exert their clinical effects through mechanisms other than monoamine reuptake inhibition. Alternatively, a low blockade of the NET and the DAT, respectively, might be sufficient for antidepressant response. These examples demonstrate that questions related to rational dosing directly allude to problems of mechanism of action (see next section).

Agonists and partial agonists: complex pharmacology for PET occupancy studies. The binding characteristics of agonists or partial agonists present other issues (see above, section Therapeutic Rationale). In many cases, agonists exert their pharmacological effects with only a few percent occupancy. The occupancy of the $\mathrm{GABA}_{\mathrm{A}}$-benzodiazepine receptor site by benzodiazepines and other drugs acting at this site is only $15-25 \%$ at full pharmacological effect, because these compounds act with a very high receptor reserve (Shinotoh et al, 1989).

A stunning example comes from the occupancy studies of the relatively new antipsychotic aripiprazole. Despite several years of the conventional wisdom that $\mathrm{D}_{2}$ DA antagonists would have antipsychotic efficacy with minimal EPS side effects within a 'therapeutic window' of $65-80 \%$ striatal $\mathrm{D}_{2} \mathrm{RO}$, the initial studies in healthy volunteers underestimated the therapeutic dose of aripiprazole. Yokoi et al (2002) constructed aripiprazole's entire dose-response curve and showed that occupancies closer to 90 or $95 \%$ were needed for the therapeutic range of the drug. This was because it was not appreciated until later that the likely mechanism of action of the drug was partial agonist at $\mathrm{D}_{2}$ receptors (Kikuchi et al, 1995). It has been theorized as to why an otherwise reasonable pre-biomarker such as $\mathrm{D}_{2} \mathrm{RO}$ did not appropriately predict the correct dose of a partial agonist (Gründer et al, 2003). As subsequently discovered, the original 'therapeutic window' of $65-80 \% \mathrm{RO}$ was valid for $\mathrm{D}_{2} \mathrm{DA}$ antagonists only (Figure 6). This example underlines that a biomarker is critically dependent on the specific mechanism of action of a certain compound. A radiotracer/pre-biomarker that has been demonstrated to predict the biological effects of a certain class of compounds might lose its validity for a drug with a slight modification of its mechanism of action, even if it binds to the same target molecule.

Similarly, many second-generation antipsychotics are partial agonists at the $5-\mathrm{HT}_{1 \mathrm{~A}}$ receptor. Aripiprazole has been recently shown to occupy only approximately $10-20 \%$ of total $5-\mathrm{HT}_{1 \mathrm{~A}}$ receptors at clinical doses (Mamo et al, 2007).In the only study with clozapine in patients with schizophrenia, this drug did not displace $\left[{ }^{11} \mathrm{C}\right]$ WAY $100,635-\mathrm{a} 5-\mathrm{HT}_{1 \mathrm{~A}}$ selective radiotracer - to a measurable extent (Bantick et al, 2004). The authors hypothesized that antagonist radiotracers like $\left[{ }^{11} \mathrm{C}\right]$ WAY 100,635 cannot be displaced by receptor agonists when these are administered in clinically tolerable doses. However, when Chou et al (2003) administered clozapine to monkeys, they measured $5-\mathrm{HT}_{1 \mathrm{~A}}$ receptor occupancies of up to $50 \%$ at the highest plasma concentrations. These authors concluded that the 5- $\mathrm{HT}_{1 \mathrm{~A}}$ receptor is a candidate target for the atypical drug actions of clozapine. As both aripiprazole and clozapine are partial agonists at the 5- $\mathrm{HT}_{1 \mathrm{~A}}$ receptor, a low occupancy of this receptor does not exclude the possibility that profound pharmacological effects are transmitted via this receptor type.

On the other hand, partial agonists with a low intrinsic activity such as aripiprazole at $\mathrm{D}_{2}$ DA receptors might need full occupancy for a clinical effect. Additional studies, possibly in conjunction with other functional biomarkers from fMRI studies, are needed to explore the relationship between RO by agonists and partial agonists and clinical effects.

Single vs multiple dosing of the candidate drug. Usually, a new investigational product is tested with single doses first, before studies with multiple dosing are performed. Although it has been shown that in many cases single-dose studies very accurately predict receptor occupancies achieved with multiple dosing, this might not be the situation for certain drugs. For example, to determine an effective antipsychotic dose of ziprasidone, the drug was administered to healthy volunteers in single oral doses of $40 \mathrm{mg}$ (Vernaleken et al, 2008). The mean striatal $\mathrm{D}_{2} \mathrm{RO}$ was $67 \%$. In a similar study, ziprasidone was administered to healthy subjects in single oral doses between 2 and $60 \mathrm{mg}$ (Bench et al, 1993). Ziprasidone $(60 \mathrm{mg})$ induced a striatal $\mathrm{D}_{2} \mathrm{RO}$ of $85 \%$. It was concluded from these studies that effective antipsychotic ziprasidone doses should be between 20 and $40 \mathrm{mg}$. Interestingly, these doses were found to be much too low clinically, where phase II clinical efficacy studies have demonstrated ziprasidone to have potent antipsychotic efficacy at $120-160 \mathrm{mg}$ and $40 \mathrm{mg}$ was not better than placebo (Goff et al, 1998). Later PET studies in patients after subchronic treatment demonstrated that the 
striatal $\mathrm{D}_{2}$ occupancy was markedly lower than was predicted by the early single-dose studies (Mamo et al, 2007; Vernaleken et al, 2008). Thus, we recommend that single-dose occupancy studies should be supplemented by subchronic studies to avoid an incorrect dose selection for large efficacy trials.

Striatal vs extrastriatal brain occupancy. Finally, the selection of the correct brain region for determination of RO has become an increasingly crucial issue. For instance, although the conventional belief of a 'therapeutic window' in the range of $60-80 \%$ striatal $\mathrm{D}_{2} \mathrm{RO}$ is true for most antipsychotics, it is now clear that low-affinity $\mathrm{D}_{2}$ antagonists such as clozapine or quetiapine occupy striatal sites to a lesser extent than extrastriatal sites, especially cortical, $\mathrm{D}_{2}$ receptors (Gründer et al, 2006; Kessler et al, 2006). These compounds very rarely occupy more than $60 \%$ striatal $\mathrm{D}_{2}$ receptors under clinical conditions. Whatever the pharmacological basis for the discrepancy between striatal and extrastriatal $\mathrm{D}_{2}$ occupancy with those compounds is, it is a likely basis for their beneficial EPS profile. This observation might be an important guide in future antipsychotic drug development.

\section{Mechanism of Action of Candidate Therapeutic Drugs}

Mechanism of action involves not only hypotheses but also actual empirical evidence for a drug candidate's effect or potential effect. One example is the potential use of DAT inhibitors in the treatment of stimulant abuse, such as methamphetamine or amphetamine abuse. Villemagne et al (1999a, b) demonstrated by PET imaging in nonhuman primates that the preadministration of the DAT inhibitor, GBR12909, blocked the amphetamine-induced DA release substantially. It was also demonstrated before the amphetamine challenge, that there was an increase of basal intrasynaptic DA, which could be useful in reducing, for example, cocaine craving. Hence, a direct ability to measure a drug action was demonstrated. Also despite some EKG limitations (QT interval lengthening), additional drug interaction trials were proceeded by NIDA in part because of the promising PET occupancy demonstrated in baboons.

Indeed, as has been suggested by others (Gomez-Mancilla et al, 2008), such imaging studies would be important to determine whether drugs not only act at their assumed targets, ie receptor target on a membrane, or potentially a second or third messenger target, but also whether they do so with sufficient occupancy (as described in the point above); and how long the receptors are occupied for other action by the therapeutic drug, ie the duration of time in which the receptors are no longer available. An illustrative example is the significant occupancy of cortical $5-\mathrm{HT}_{2 \mathrm{~A}}$ receptors with 10 or $20 \mathrm{mg}$ single doses of oral MDL 100907, a selective $5-\mathrm{HT}_{2 \mathrm{~A}}$ receptor antagonist, as compared to the much more rapid plasma washout in humans (Figure 5,

Figure 1. This figure legend is an example of how imaging can be used in human drug discovery and development to support PoC and early translational development. Here we give a hypothetical example of a new drug that has just been developed and is being tested in vivo. This initial testing could be done in rodents and nonhuman primates, but the specific figure describes the applications once it enters into humans. On the left path, we have a hypothetical drug where the mechanism of action has already been hypothesized or known based on preclinical models. We then determine if it is receptor- or a transporter-mediated mechanism as is the case in many central nervous system (CNS) drugs. Alternatively, it may be an enzyme-mediated mechanism. In either of these two cases, the paths for decision-making are considered the same. For instance in the receptor case, if a minimum receptor occupancy $(\mathrm{RO})$ is already known (for most antipsychotics it is 60-70\%, with a few exceptions such as aripiprazole, clozapine, and quetiapine), then just in time dosing (where doses are given to quickly achieve the $70 \%$ or higher level or bracketed) would be performed. The dose that would achieve the minimum therapeutic level (ie $60-70 \%$ in the case of a $D_{2}$ dopamine antagonist antipsychotic) would then be employed in future phase IA and II studies. Conversely, if a minimum RO is not known, such as was the case with the NK-1 receptor, a full range of receptor occupancies would be obtained at doses that were below the maximum tolerated dose (MTD) determined by other phase I human safety studies and animal studies. If the RO is at least 10-15\%, then dosing up to the MTD would be a typical approach. However, in some cases, not even 10-15\% occupancy is obtained and dosing may already be at an $\mathrm{ED}_{50}$ or at MTD, thereby precluding further dosing. As doses as low as $10 \%$ may be technically within the range of error at these low occupancy levels, this drug would be very suboptimal and might be canceled based on this situation. (It has to be stated that in the case of a receptor ligand, this flow chart is true for an antagonist only; agonists or partial agonists with high intrinsic activity may exert full pharmacological effects at much lower RO. In this case, the correct path might be approached right from the beginning. However, even for a full agonist, determination of an RO that exceeds the test-retest variability for a given radiotracer would be a meaningful task. For further discussion, see text). Analogously, the same argument can be made for enzyme activity (EA) where there may be a minimum EA that could be measured (eg acetylcholinesterase activity), which if at a very low level and already at significant side effects, close to MTD could justify termination of drug development. Another possibility is where the mechanism of action is definitely known or hypothesized as non-RO or non-EA. In this case, some less specific measurements such as fMRI-BOLD response or PET-glucose metabolism would be used. If a measurable effect is obtained, then additional dosing could be determined if a dose response occurs. If no measurable effect is obtained with a number of more generalized imaging measures, this may give some indication of concern about pharmacological action and possible stopping of drug development. The second decision point in this development, shown on the right path, is if the mechanism of action is not known or hypothesized, then in this case it is unclear whether receptor-mediated function or an enzyme-mediated function, etc is operative. Some examples of this might be the efficacy of anesthetics where the mechanism of action is not well understood, or the efficacy of anticonvulsants in bipolar disorder. In some cases, it may be a second or third messenger effect that is not easily measurable by imaging or is not clearly well defined. In this case, it may be possible to generally screen with either fMRI-BOLD response or PET-glucose metabolism. Alternatively, if a series of neurotransmitters are expected but no single neurotransmitter is specifically known (eg a number of neurotransmitters might be implicated with no clear dominance), then a screen with validated PET radioligands might be employed in an iterative fashion. If this screen reveals no measurable occupancy or EA, this might be grounds for stopping the drug. However, if some occupancy is measurable dose dependent and is within or below the MTD level, this could constitute a signal to continue to study the drug in further human trials. This component is approaching the role of imaging biomarkers in early drug development or translational studies. Although specific to imaging in this chart is $(\mathrm{RO})$ and $(\mathrm{EA})$ and some more general functional measures, analogous approaches could be argued for target engagement in general, using other imaging approaches and perhaps nonimaging. 
Gründer et al, 1997). Similarly, it has been demonstrated that the atypical antipsychotics olanzapine and risperidone showed an apparent dissociation of their brain and plasma kinetics, leading to sustained high blockade of both striatal and extrastriatal D2 receptors for a much longer time than one would have predicted based on their plasma elimination half-life (Tauscher et al, 2002). Another clinically important example is the observation that $\mathrm{D}_{2}$-like $\mathrm{DA}$ receptors remain occupied by aripiprazole for up to 7-10 days after termination of drug administration in some patients with high plasma concentrations (Figure 2, Gründer et al, 2008). Finally, imaging studies may indicate the type of cellular or molecular response that occurs. This could be explored, for example by using other PET techniques (eg measuring glucose metabolism or oxygen metabolism), to shed some light on this. The PET brain imaging measures would be further strengthened by the addition of appropriate pharmacokinetic and behavioral correlates (see Figure 1, right-sided aim).

One of the shortcomings of determining TE or RO with $\mathrm{PET} / \mathrm{SPECT}$, as the example with aripiprazole showed, is that those techniques do not inform about the intrinsic activity at the target or about functional 'downstream' effects. Other imaging modalities such as fMRI, which

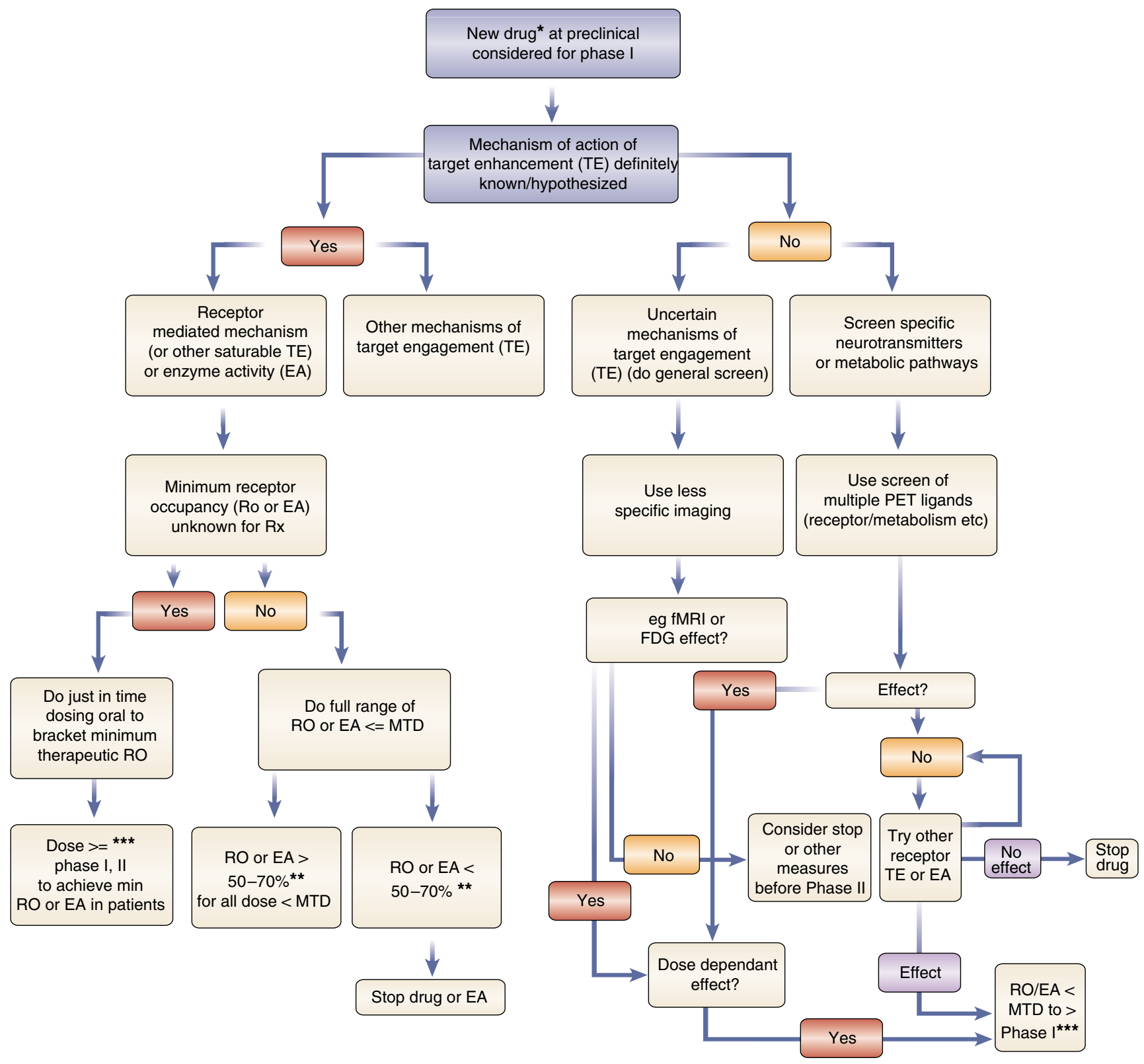

* Shows desired preclinical model prediction of clinical effects for treatment condition.

**Depending on preclinical assays showing target engagement (eg occupancy),

$50-70 \%$ for full antagonists; $40-60 \%$ for inverse agonists less for agonist/ partial agonist

${ }^{\star * \star}$ At this stage future target / drug testing may be indicated $>=$ phase 1 and beyond 
demonstrates modification of the BOLD signal with therapeutic drugs at their hypothesized regional brain sites of action, have sought to address those gaps by determining functional brain responses representative of activation or deactivation patterns of certain brain regions to establish 'brain circuits' responsible for processing information in a given symptom or syndrome domain. Indeed, the proof of TE of agonists and partial agonists could be a major domain of fMRI. This technique probably allows for generation of mechanism-specific activation maps (fMRI fingerprinting; Borsook et al, 2006). One such example is that fMRI findings have contributed to our current understanding of pain processing and analgesia: fMRI studies of acute and chronic pain have found numerous regions of the brain to be involved in the interpretation of the 'pain experience'; studies in chronic pain conditions have identified a significant CNS component; and studies of surrogate models of chronic pain are also being used to further this understanding. Furthermore, studies of endogenous pain processing include the use of fMRI to evaluate the effects of analgesics on brain function in acute and chronic pain (for review see Borsook et al, 2006). We note that fMRI could also be used in the presence of, for example, visual exposure to cues such as sad and happy faces for antidepressants or for drugs or alcohol in the case of substance abuse/alcohol craving. Although it may be used more often in the demonstration stage, fMRI does seem to have promise for some drug development approaches (Borsook et al, 2006; Ireland and Williams, 2006).

However, fMRI technology and research needs to address some fundamental issues before usefulness of fMRI for drug development can be adequately judged. Major short comings at the moment include uncertain reproducibility; test-retest reliability has not been consistently demonstrated across fMRI paradigms; as well as a clear understanding of the variability of the BOLD signal in relationship to the detected effects, or in other words a

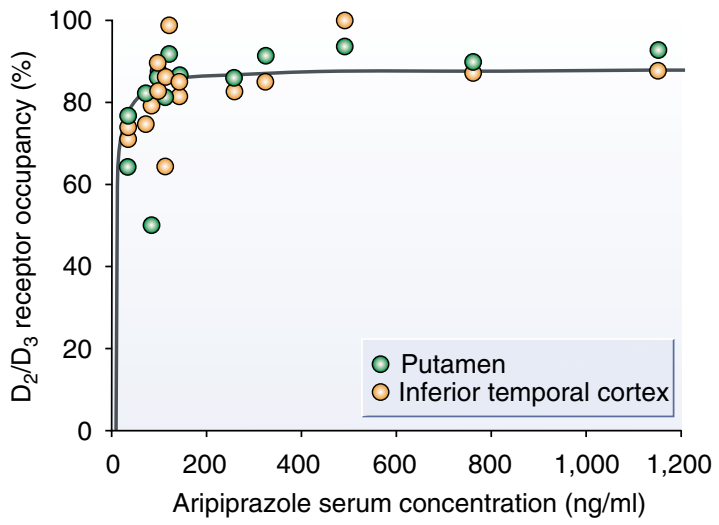

Figure 2. Relationship between aripiprazole serum levels ( $x$ axis) and dopamine $D_{2} / D_{3}$ receptor occupancy in the putamen ( $y$ axis, green circles) and in the inferior temporal cortex (yellow circles) in 16 patients with schizophrenia and schizoaffective disorder receiving therapeutic doses of aripiprazole. Please note that these relationships are described by the same regression line (Modified after Gründer et al, 2008). better understanding about powering fMRI studies to get to reasonable effects sizes useful for decisions in drug development. It is our belief that such areas go well beyond the capacity of a single researcher or a single site, and are thus best addressed through research collaborations and public-private partnerships. The latter, in conjunction with industry partners, provides the opportunity to test novel compounds in well-devised fMRI paradigms addressing the noted issues about reproducibility and standardization of

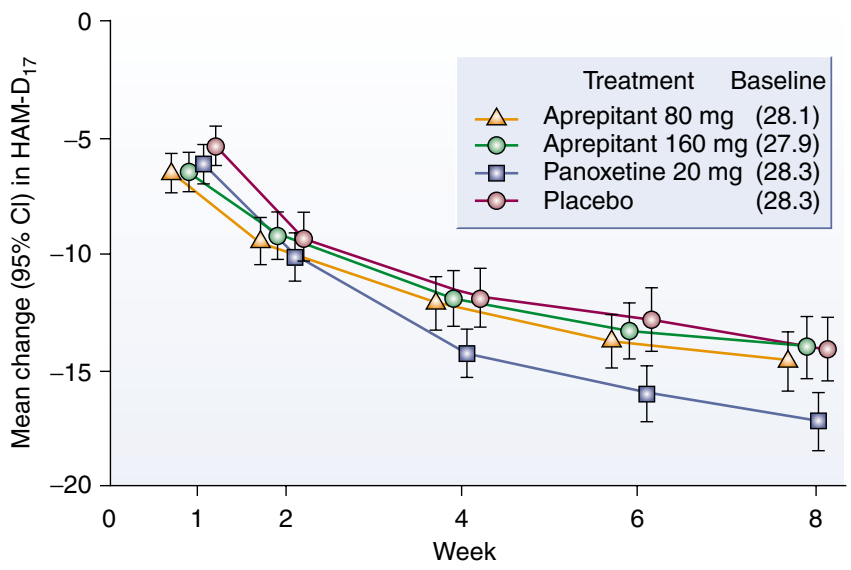

Figure 3. Results of 8 weeks' treatment with aprepitant, paroxetine, or placebo in major depressive disorder. Mean change from baseline (95\% confidence interval, Cl) total score on first 17 items of the Hamilton Rating Scale for Depression (HAM-D $\left.{ }_{17}\right)$ at each evaluation time point in Study 062; last-observation-carried-forward approach. Paroxetine is significantly better than placebo $(p \leqslant 0.05)$, whereas aprepitant is not significantly better than placebo.
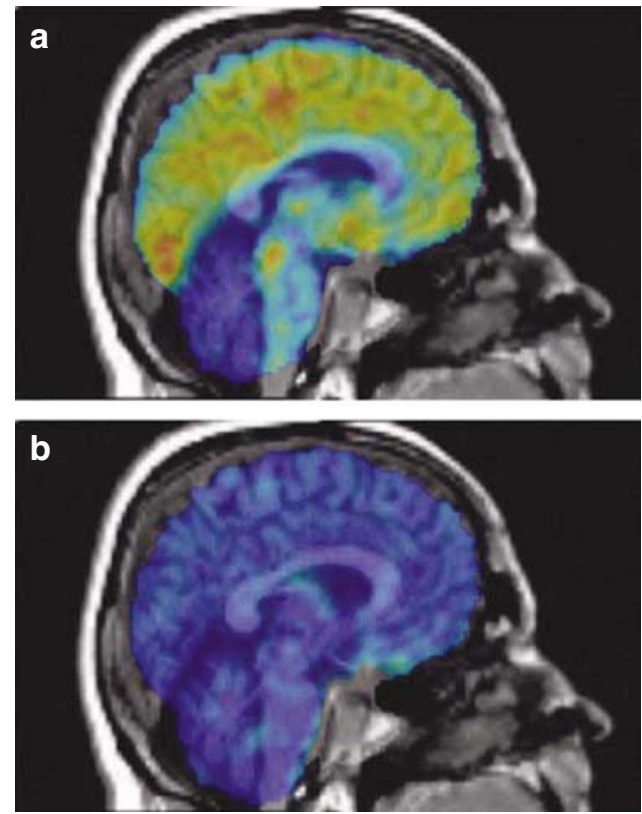

Figure 4. PET scans of brain neurokinin 1 receptors, visualized with $\left[{ }^{18} \mathrm{~F}\right] \mathrm{SPA}-\mathrm{RQ}$ overlaid on magnetic resonance images before (a) and after (b) blockade by administration of $160 \mathrm{mg}$ aprepitant for 40 days. Blue indicates low tracer binding, yellow and orange indicate high tracer binding. The study clearly indicates that NK-1 receptors are almost completely blocked by aprepitant in this patient (Modified from Keller et al, 2006). 


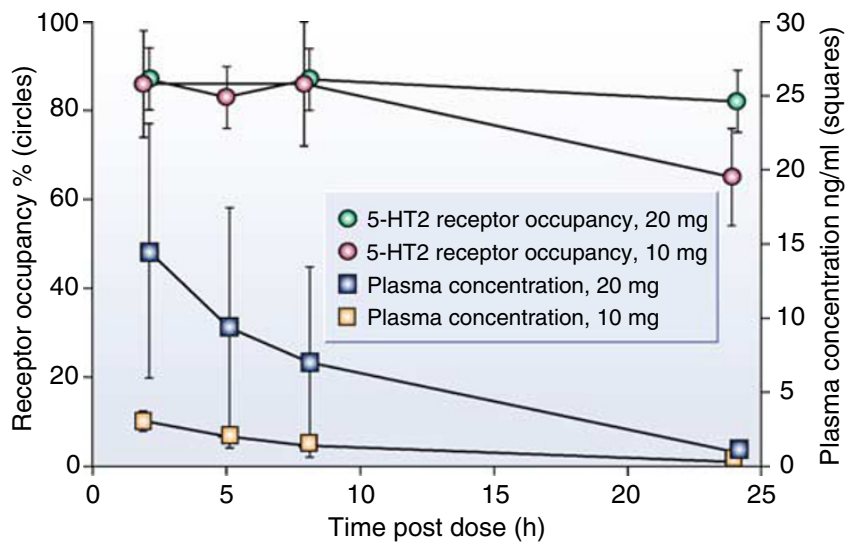

Figure 5. Time course of 5- $\mathrm{HT}_{2}$ receptor occupancy in the frontal cortex (mean $\pm \mathrm{SD}$ ), expressed in percent decrease in binding potential $\left(k_{3} / k_{4}\right)$ from baseline (left $y$ axis, represented by circles), and plasma concentrations for 10 and $20 \mathrm{mg}$ oral doses of MDL 100907 (right $y$ axis, represented by squares). Binding potential was calculated with the graphical method described by Logan et al (1990). Modified after Gründer et al (1997)

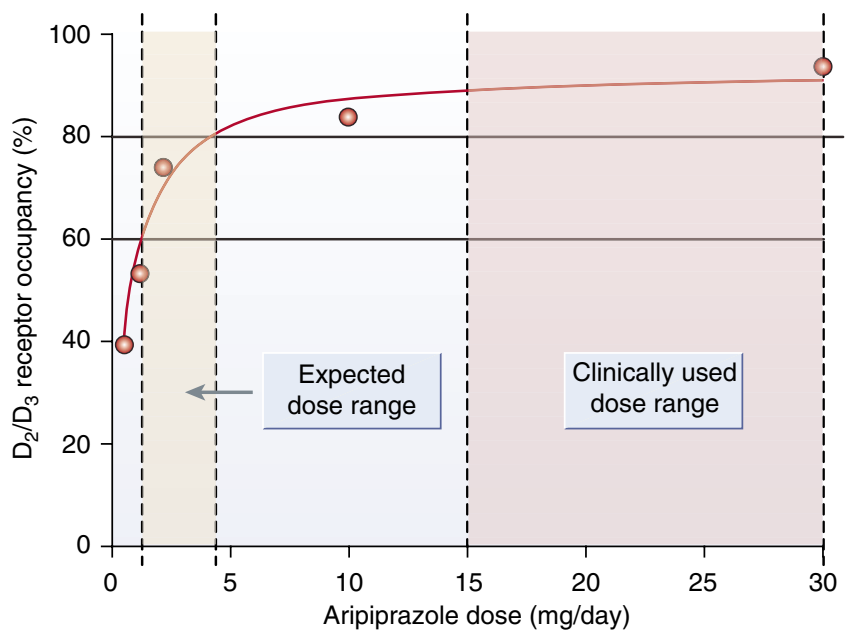

Figure 6. Relationship between aripiprazole daily dose, $D_{2} / D_{3}$ receptor occupancy $(\mathrm{RO})$ in putamen, and clinically expected and used aripiprazole doses. Mean $\mathrm{RO}$ values in putamen at a given dose were taken from Yokoi et al (2002) and fit to a simple $B_{\max }$ model by nonlinear regression assuming a one site saturation. Horizontal lines indicate the hypothesized 'therapeutic window' between 60 and $80 \%$ striatal $D_{2} R O$ suggested by Farde and colleagues (1992). The bright shaded area ('expected dose range') designates the dose range that should lead to $\mathrm{RO}$ within this 'therapeutic window', whereas the dark shaded area ('clinically used dose range') indicates the dose range that has been proven to have antipsychotic efficacy. (Modified after Gründer et al, 2003).

paradigms, hereby clarifying the extent to which pharmacofMRI is a useful tool for drug development.

\section{EXAMPLES OF IMAGING PRE-BIOMARKER/ BIOMARKERS}

Some biomarkers (type 0 ) may track the natural history of the disease and correlate longitudinally with the disease course. Examples of this may be PET with $\left[{ }^{18} \mathrm{~F}\right]$ FDG for regional cerebral glucose metabolism, tracking the course of hypometabolism in the parietal/temporal cortex in worsening dementia (Foster et al, 2007), or the gradual reduction that occurs in the basal ganglia of patients with Huntington's disease (HD). Quantification of striatal DA synthesis capacity with $\left[{ }^{18} \mathrm{~F}\right]$ FDOPA or of striatal DAT with selective DAT ligands can be considered type 0 markers for neuronal integrity/loss in Parkinson's disease (PD). PET with $\left[{ }^{15} \mathrm{O}\right] \mathrm{H}_{2} \mathrm{O}$ or fMRI imaging are able to show reductions in cerebral blood flow over time in the natural course of stroke (and perhaps later luxury perfusion upon some attempts of the revascularization after stroke). Ideally, a type 0 biomarker is sensitive to treatment-induced changes, which would then qualify it for a type 2 biomarker.

Other imaging methods are hoped to become the ultimate 'surrogate end points' as in this type (2), ideally the change in the putative biomarker is predictive of clinical outcome. The efficacy of a specific treatment should be reflected in changes in the biomarker. The validation of these potential biomarkers thus implies the existence of an effective treatment (Frank and Hargreaves, 2003). There is hope that certain radiotracers and MRI may in fact provide this value. However, for the so-called 'functional psychoses', ie schizophrenia and (bipolar) affective disorder, which most likely do not represent disease entities but heterogeneous groups of diseases, biomarkers in its general sense might even not exist. Biomarkers for these diseases might always just represent certain aspects of its phenomenology (eg cognitive deficits in schizophrenia).

However, neurodegenerative disorders with largely welldefined histopathology seem to be ideal targets for type 2 biomarker developments. Molecular targets resembling the integrity of the dopaminergic synapse belong to the most accepted biomarkers in PD. These methods have been demonstrated in many studies to reliably distinguish patients with the disease from healthy controls (Parkinson Study Group, 2000a). Longitudinal studies with these markers clearly show a progressive decline with disease progression. Moreover, they are powerful tools for early disease identification. For example, PET with $\left[{ }^{18} \mathrm{~F}\right] \mathrm{FDOPA}$ is able to detect asymptomatic preclinical stages of neurodegeneration in unaffected twins of PD patients (Burn et al, 1992). However, neither $\left[{ }^{18} \mathrm{~F}\right] \mathrm{FDOPA}$ nor tracers for the DAT has been convincingly demonstrated to be sensitive to putative neuroprotective therapy or to be reflective of clinical benefit of a specific treatment. In the CALM-PD trial, patients with PD were treated with either L-DOPA or the DA agonist pramipexole (Parkinson Study Group, 2000b). In a subgroup of the study population, treatment was monitored with SPECT with $\left[{ }^{123} \mathrm{I}\right] \beta$-CIT, a nonselective ligand for DA and SERT (with binding in the striatum representing binding to the DAT). Although the decline in tracer binding was significantly lower in patients treated with pramipexole (16 vs $26 \%$ in the L-DOPA group; Parkinson Study Group, 2002), this did not translate into a clear clinical benefit in the total group (Parkinson Study Group, 2000b). Similarly, the ELLDOPA trial, which 
compared three doses of L-DOPA with placebo, showed that patients on the highest dose of L-DOPA had the most rapid decline in $\left[{ }^{123} \mathrm{I}\right] \beta$-CIT binding, although they had the best clinical improvement (Fahn et al, 2004). The REAL PET trial used PET with $\left[{ }^{18} \mathrm{~F}\right]$ FDOPA for monitoring of treatment with the DA agonist ropinirole in comparison with the standard drug L-DOPA. After 2 years of treatment, the ropinirole group had less decline in tracer uptake $(13 \mathrm{vs}$ $20 \%$ ), but patients treated with L-DOPA presented with better functional outcome (Whone et al, 2003).

Long-term studies are needed to clarify whether the favorable biomarker measures of some of the new treatments translate into long-term benefits that were not detected in the above-mentioned trials. These examples demonstrate that the relationship between clinical outcomes and the behavior of these biomarkers is not well understood. Drug development with pre-biomarkers and biomarkers has to be complemented by thorough clinical evaluation, and clinical trial design and biomarker development have to go hand in hand. Finally, the expectation would be that certain imaging biomarkers such as the current efforts to image amyloid plaques and tangles in dementia and $\mathrm{AD}$ might eventually lead to diagnostic radiotracers which could be used to impact critical decision-making in health care. FDG is already accepted as a decision-making tool for a limited diagnosis in some areas of dementia, by the federal CMS and US health insurance industry, just as FDG is reimbursable for some aspects of abdominal, head, and neck cancers.

In the area of $\mathrm{AD}$, it is the hope that imaging tools such as $\left[{ }^{18} \mathrm{~F}\right]$ derivatives of $\left[{ }^{11} \mathrm{C}\right] \mathrm{PIB}$, or other $\left[{ }^{18} \mathrm{~F}\right]$-labeled PET ligands for amyloid imaging, or perhaps next-generation tracers beyond $\left[{ }^{18} \mathrm{~F}\right]$ FDDNP (which may label neurofibrillary tangles and aggregated amyloid plaques) might be used to help in the differential diagnosis of the dementias and eventually used to track treatment outcome in the absence or presence of dementia medications. This could become a truly 'diagnostic' biomarker. These new PET agents for imaging aggregated $\beta$-amyloid plaques and potentially neurofibrillary tangles may be used to help not only track early dementia but help identify those populations that may benefit from early intervention with the putative diseasemodifying therapies (eg $\beta$ - and $\gamma$-secretase inhibitors and vaccination), currently being developed for future treatment of $\mathrm{AD}$ and other dementias. Early intervention in neurodegenerative disorders, even in presymptomatic stages, may be of considerable benefit, and therefore identification of these biomarkers is of key importance. It has been calculated that a delay in onset of AD by 5 years could reduce disease prevalence by $50 \%$ (DeKosky and Marek, 2003). If the disease could be delayed by 10 years, it would almost disappear. Here is where demonstrating the PoC is of value, especially to determine whether an early imaging pre-biomarker/biomarker has characteristics as a potential clinical biomarker, which implies its sensitivity to diseasemodifying therapy. These imaging agents show significant differences in binding in well characterized $\mathrm{AD} v s$ healthy controls and some overlap in subjects with mild cognitive impairment (MCI) (Rowe et al, 2007), however, there is insufficient evidence that the earliest plaque imaging agents such as $\left[{ }^{11} \mathrm{C}\right] \mathrm{PIB}$ change or progress over time with disease severity (something that does appear to occur with $\left.\left[{ }^{18} \mathrm{~F}\right] \mathrm{FDG}\right)$. Thus, the next generation of such $\beta$-amyloid plaque-imaging PET agents may have the ability to demonstrate disease progression.

In the ADNI there is anticipation that serial $\left[{ }^{18} \mathrm{~F}\right] \mathrm{FDG}$ imaging over 3 years will capture some of the natural progression of the disease and will help predict early on these effects, which might in turn provide a baseline for examining the outcome of early therapeutic treatment. Similarly, MRI and MRS imaging are increasingly being used for early (and probably) presymptomatic detection of neurodegenerative diseases and monitoring of disease progression. This includes volumetric MRI to detect both global and local brain atrophy in AD (Fox et al, 2001). It is anticipated that some areas such as volumetric MRI-as in the case of hippocampal volumes for atrophy in dementia - might eventually approach a surrogate marker status, although most imaging techniques have not gained this level of acceptance, let alone registration. MRS has been shown to be of value in the detection of early changes in energy metabolism, such as those occurring in HD (Jenkins et al, 1998). Amyloid plaque imaging by MRI is nonetheless still in an experimental stage (Benveniste et al, 1999; Hintersteiner et al, 2005). A final example for which MRI has been helpful is in MS, where it has been used to evaluate the use of interferon-1- $\beta$ and has shown the value of early intervention (Jacobs et al, 2000). None of these biomarkers, though, has been unequivocally shown to be sensitive to change with treatment.

\section{REJECTING A DRUG CANDIDATE USING IMAGING METHODS}

An example where imaging helped to reject a target is the NK-1 receptor antagonist aprepitant. Although initial studies showed promise for aprepitant in depression (Kramer et al, 1998), subsequent trials did not show efficacy in the treatment of major depressive disorder (Figure 3, Keller et al, 2006), despite both doses tested in depression, 80 and $160 \mathrm{mg}$ per day showed almost complete saturation of the target with occupancy rates in excess of $90 \%$ in a PET study with $\left[{ }^{18} \mathrm{~F}\right] \mathrm{SPA}-\mathrm{RQ}$ (Figure 4 ).

Another example from industry was the development of a PET tracer to assess the ability of an antiobesity drug candidate to engage brain NPY5 receptors (Erondu et al, 2006). NPY5 receptors are thought to be critical components of a pathway that stimulates food intake and decreases energy expenditure. Despite full TE of the therapeutic target, however, the degree of weight loss induced using the drug candidate alone was relatively modest and thus not clinically meaningful. Further development of this drug candidate would not produce 
therapeutic value, which resulted in the company's reprioritization of the target and project.

These examples illustrate the important role of $\mathrm{RO} / \mathrm{TE}$ imaging studies. If a drug candidate under clinical development shows near-maximal target saturation and does not display clinical efficacy, then the concept of that particular target playing a role to treat a certain pathology or disease can be refuted with confidence and without second guessing whether adequate doses were given to test the hypothesis. However, if a drug candidate does not occupy the receptor or enzyme anticipated to be the site of action, even at levels near maximum tolerated dose, then such imaging studies can suggest stopping further investigation without proceeding to efficacy trials in patients. Thus, as a screen for early phase I development, the lack of displacement of a validated radiotracer could be an important indicator that the drug will not likely be efficacious in any dose that is considered tolerated or safe for further clinical trials.

\section{TWO HYPOTHETICAL CASES FOR IMAGING BIOMARKERS/PRE-BIOMARKERS FOR EARLY DRUG DEVELOPMENT PROOF-OF- CONCEPT/PROOF-OF-DRUG CANDIDATE}

\section{Case 1: Drug Mechanism has been Established but Proof-of-Drug Candidate is Uncertain}

In this general example, the target neurotransmitter system (eg DA, 5-HT, GABA, etc) may already be known based on animal models and a 'lead drug' is about to be tested, defined here as '[LEAD]'. To establish its PoDC, it has been determined that there exists an imaging biomarker such as a PET/SPECT radiotracer to measure the RO of this lead drug [LEAD] background. This hypothetical case uses a radiotracer $\left[{ }^{11} \mathrm{C}\right] \mathrm{BIOM} 1$, which will be tested in early clinical phase I studies to determine whether it can be used to measure the $\mathrm{RO}$ of hypothetical receptor ' $\mathrm{X}$ ' or ' $\mathrm{X}_{1}$ ' (subtype of receptor $\mathrm{X}$ ).

Before this, multiple ligands were identified in the library of the [LEAD] sponsor that were expected to bind to the same site and could be useful for competitive RO studies. In some cases these derivatives come from the library of the pharma or academic center that holds the drug, but in many cases it is the third party radiotracer either documented in the literature or one that is partially in development. Through small animal PET imaging using baboons and multiple pharmacological studies using the [LEAD] or derivatives of the [LEAD], it has been demonstrated that occupancy can be achieved in nonhuman primates with PET/SPECT imaging.

Hence, this subsequent study is the human PoC with a radiotracer, where:

(a) The usual characteristics are as an open label, one imaging site, and single or repeat administration of the radiotracer $\left[{ }^{11} \mathrm{C}\right]-\mathrm{B} 10 \mathrm{M} 1$ in healthy human volunteers. (b) The objectives are to test the feasibility of whether this radiotracer can image the appropriate receptor sites with sufficient specificity and sensitivity, and has favorable characteristics of a radiotracer including pharmacokinetic properties, metabolism, and favorable tests-retests.

(c) The usual numbers of subjects range from 5 to 15 volunteers.

If less than 30 subjects are employed, the study would fall under the eIND (Exploratory IND) procedure recently developed by the FDA. If more than 30 subjects are anticipated, this may go into the 'full IND category'. For the former example, ie an eIND, radiation dosimetry, safety pharmacology, and imaging efficacy are among the end points typically sought (Mills, 2008).

Before the IND submission, depending on whether it is an eIND or a full IND, one or two species with a safety profile of at least 100-1000 times the expected radiotracer mass are injected. The latter mass is determined by the specific activity that typically has been achieved in preclinical studies. This quantity (the measure of the ratio of the number of unlabeled atoms of the putative radiotracer that are radioactively labeled) can determine how small an amount can be injected. Usually a minimum amount of radioactivity (eg $15-20 \mathrm{mCi}$ for $\left[{ }^{11} \mathrm{C}\right]$ and $2-5 \mathrm{mCi}$ ) for $\left[{ }^{18} \mathrm{~F}\right]$ ) is required for imaging in a brain PET scanner commercially available for human studies. This is especially true for early PoC studies where dynamic PET imaging is carried out over $90-120 \mathrm{~min}$ and sufficient radioactivity is needed over time frames as short as $15 \mathrm{~s}$ and as long as $20-30 \mathrm{~min}$ to obtain a time activity curve from which the receptor parameters are modeled. Hence, the typical injected mass dose of the radiotracer is not uncommonly between 1 and $20 \mu \mathrm{g}$ for a typical 400-500 molecular weight radioligand. Under most circumstances, this is a no effect level (NOEL) mass dose but toxicology with safety at least 100-1000 times this.

A typical study design consists of initial imaging almost always parallel with arterial sampling of the injected radioactivity to obtain the input function for initial mathematical modeling of receptor parameters. Depending on the receptor system involved, a reference region (eg the cerebellum in the case of $\mathrm{D}_{2} / \mathrm{D}_{3} \mathrm{DA}$ imaging) may exist to simplify the modeling. But before this, arterial sampling for the input function together with a dynamic brain curve are the two variables used in mathematical models to derive receptor density and affinity (ie distribution in volumes or binding potential) pre-IND from which the receptor quantification is derived. Depending in part on requirements by the FDA and perhaps on the prior evidence for radiation burden from rodent and nonhuman primate studies, whole-body radiation dosimetry studies in humans may be needed as the first step. In lieu of an explicit requirement, it is reasonable to first initiate scans in 2-3 humans to verify that the tracer gets into brain and distributes in a fashion expectant with post-mortem human or animal biodistributions of the receptor. If it should fail 
this test of sufficient uptake or expected brain distribution, the radiation dosimetry measurements may not be needed as the trial may end at this point. Alternatively, should this be successful, a larger radiation dosimetry study can be carried out normally using a PET CT whole-body scanner, whereas other dynamic studies are carried out on brain only, to further interrogate the receptor binding properties of the candidate radioligand. Additional brain studies include testretest, where variability under $15-20 \%$ is expected to be the minimum criteria (many radiotracers are under 10\%).

Finally, some trials may take the final step of demonstrating specific binding of the candidate radiotracer in early human studies (ie using a known blocker of the radiotracer either in market or the derivative or the [LEAD] compound or the [LEAD] compound itself), which is dependent on whether the IND has been filed for the lead compound (or in the case of non-US centers, where the approval for the [LEAD] as well as the radiotracer has been appropriately approved by the governmental agencies). In these studies, at least 1-2 doses - a low and a high dose of [LEAD] - may typically be employed to demonstrate selective occupancy or a dose response to the unlabeled blocker against the putative radiotracer $\left[{ }^{11} \mathrm{C}\right.$ BIOM1].

If the radiotracer has been shown useful and effective (as studied in earlier PoC trials), it may be used explicitly in establishing the rational dose for the [LEAD] for future phase IB, and phase II and other trials. This is often established with just in time dosing where the radiotracer is administered during a baseline followed by a repeat PET scan after administration of the [LEAD] acutely or chronically. After an initial [LEAD] dose has been given, the data are quickly analyzed in duplicates or triplicates along with the corresponding pharmacokinetic plasma data to determine the degree of occupancy at that plasma concentration. From this point, doses can be adjusted upward or downward to obtain an entire dose-response curve efficiently. In some wellestablished areas, such as the development of an atypical antipsychotic based on experience with typical antipsychotics, $\mathrm{D}_{2}$ DA occupancy might already be established.

Finally, the choice of acute $v s$ chronic dosing, especially in the case of antipsychotics, is still a controversial one. The obvious advantage of the acute dosing for occupancy may be restricted by the amount of safety data for the [LEAD] drug already existing as the biomarker validation for the radiotracer may take place in parallel with the [LEAD] early development. As noted earlier, in some cases (Vernaleken et al, 2008), acute single dosing may not be adequately predictive of future chronic dose. Therefore, for early PoC, acute dosing may be sufficient, but before moving on to patient studies - chronic dosing either in some healthy volunteers or a small group of the patient population may be indicated.

\section{Case 2: Hypothetical Example Where the Proof of Concept of the Target is Uncertain}

An imaging example that examines imaging pre-biomarkers, such as change in brain activation using fMRI and reduction or change of such brain activation during drug administration, is relevant in the circumstance where the $\mathrm{PoC}$ of the target is uncertain. One of the best-documented examples is the dysfunctional activation of the amygdala in response to fearful stimuli. Subjects with at least one copy of the short allele of the SERT promoter polymorphism, which has been associated with reduced SERT expression and function, and-consequently - increased anxiety-related traits (Lesch et al, 1996), demonstrate greater fMRI BOLD activation in response to fearful stimuli as compared to subjects with two copies of the long allele (Hariri et al, 2002). This polymorphism, which represents the genetic basis for the functional reactivity of the amygdala, is now considered as a susceptibility factor for affective disorders (Hariri et al, 2005). Most interestingly, the SSRI antidepressant citalopram reduced amygdala activation in response to fearful threats in normal volunteers (Harmer et al, 2006). Thus, the amygdala response to fearful stimuli could develop into a pre-biomarker for antidepressant effects (Staner, 2006). However, it is presently unclear whether this paradigm is also valid for antidepressants with a (supposedly) nonserotonergic mechanism of action. Another brain region for which the response to specific emotional stimuli might predict antidepressant treatment response is the anterior cingulate cortex (Fu et al, 2004). The ultimate usefulness of these paradigms to provide surrogate markers has to be tested over a wide range of different pharmacological mechanisms. As with schizophrenia, it is likely that the heterogeneous group of depressive disorders is best characterized by an array of different endophenotypes, each of which has to be characterized by a specific biomarker, that include but are not limited to imaging (Staner, 2006).

\section{FUTURE DIRECTIONS AND CHALLENGES}

The greatest challenges for molecular imaging methods, especially radiolabeled tracers for PET and SPECT are finding suitable ligand that provide the appropriate TE to allow a meaningful PoC/proof-of-mechanism study. All too often as new biological targets become available their insufficient radioligands to obtain such engagement. This is in part because the targets often novel have only a very small number of compounds that have the facility to enter the brain including crossing the BBB and bound to be appropriate. It targets especially in the CNS. More difficult is finding suitable radioligands that have the appropriate kinetic properties (binding and metabolism, etc), and signal to noise such that they can be quantified using existing imaging instrumentation and mathematical modeling. An important consideration is that many of these targets are increasing targets of interest amongst many pharma and academic institutions and therefore the sharing of such scarce resources either preclinically in terms of joint development (eg the Biomarker Consortium idea), or the potential sharing in an early discovery translational phase where intellectual properties may be of considerable 
concern including trade secrets but could be done in a trusted environment (eg the Radiotracer Clearinghouse)see references McCormick et al (2007) and Davis et al (2008).

A further challenge is that the resources and efforts should be made and recognized as being useful by pharma and academia. For example, the recent mGLuR2,3 agonist treatment for schizophrenia (reference) could have been potentially aided by PET biomarker measurement for occupancy to help determine the dose of this complex target where there is a wide dose range with little information. If chemistry efforts and development of ratiotracers could be done in parallel with discovery of therapeutic molecules, the true efficiency of such potential PET/SPECT biomarkers could be realized.

\section{SUMMARY}

Imaging, especially PET and molecular imaging have a very special role in aiding PoC determinations to CNS drug development. Sharing of radiotracers is likely to promote and optimize their use, thereby enabling widespread recognition in the field and ultimately facilitating regulatory acceptance of imaging biomarkers.

\section{ACKNOWLEDGEMENTS}

This study was supported by NIH RO1 AA12839 NIAAA, NIDA K24 DA00412-01A1, NIMH 9R01MH078175-04A1; Lilly Research Labs; special thanks to $\mathrm{Dr}$ Richard Hargreaves and Dr Donald Burns of Merck Research Labs for significant comments and advice.

\section{DISCLOSURE/CONFLICT OF INTEREST}

The authors declare that over the past 3 years:

Dr Wong has received grant support from The National Institutes of Health, Acadia, Amgen, Avid, Bristol Myers Squibb, The DANA Foundation, Eli Lilly, Intra-cellular therapies, Johnson \& Johnson, Orexigen, Philip Morris, Roche and Sanofi-Aventis.

Dr Tauscher is an employee of Eli Lilly and Company.

Dr Gründer has served as a consultant for AstraZeneca (London, UK), Bristol-Myers Squibb (New York, NY), Johnson \& Johnson (Beerse, Belgium), Otsuka (Rockville, $\mathrm{MD}$ ), and Pfizer (New York, NY). He has served on the speakers' bureau of AstraZeneca, Bristol-Myers Squibb, Eli Lilly (Indianapolis, IN), Janssen Cilag, Otsuka, Pfizer, Servier (Paris, France), and Wyeth (Madison, NJ). He has received grant support from Alkermes (Cambridge, MA), BristolMyers Squibb, Eli Lilly, Johnson \& Johnson, and Pfizer.

\section{REFERENCES}

ADNI (2008). Available at: http://www.nia.nih.gov/Alzheimers/Researchlnformation/ ClinicalTrials/ADNI.htm.

Atkinson AJ, Colburn WA, DeGruttola VG, DeMets DL, Downing DJ, Hoth DF et al, Biomarkers Definitions Working Group (2001). Biomarkers and surrogate endpoints: preferred definitions and conceptual framework. Clin Pharmacol Ther 69: 89-95.
Bantick RA, Montgomery AJ, Bench CJ, Choudhry T, Malek N, McKenna PJ et al (2004). A positron emission tomography study of the 5-HT1A receptor in schizophrenia and during clozapine treatment. J Psychopharmacol 18: 346-354.

Baumann P, Hiemke C, Ulruch S, Eckerman G, Gaertner I, Gerlach M et al (2004). The AGNP-TDM expert group consensus guideline: therapeutic drug monitoring in psychiatry. Parmacopsychiatry 37: 243-265.

Bench CJ, Lammerstsma AA, Dolan RJ, Grasby PM, Warrington SJ, Gunn K et al (1993). Dose dependent occupancy of central dopamine D2 receptors by the novel neuroleptic CP-88,059-01: a study using positron emission tomography and 11C-raclopride. Psychopharmacology 112: 308-314.

Benveniste H, Einstein G, Kim KR, Hulette C, Johnson GA (1999). Detection of neuritic plaques in Alzheimer's disease by magnetic resonance microscopy. Proc Natl Acad Sci 96: 14079-14084.

Borsook D, Becerra L, Hargreaves RJ (2006). A role for fMRI in CNS drug development. Nat Rev Drug Discov 5: 411-424.

Bowie CR, Reichenberg A, Patterson TL, Heaton RK, Harvey PD (2006). Determinants of real-world functional performance in schizophrenia subjects: correlations with cognitive, functional capacity, and symptoms. Am J Psychiatry 163: 425.

Burn D, Mark MH, Playford ED, Maraganore DM, Zimmerman T, Duvoisin RC et al (1992). Parkinson's disease in twins studied with 18F-dopa and positron emission tomography. Neurology 42: 1894-1900.

Chou YH, Halldin C, Farde L (2003). Occupancy of 5-HT1A receptors by clozapine in the primate brain: a PET study. Psychopharmacology 166: 234-240.

Davis M, Hanson S, Altevogt B (2008). Neuroscience biomarkers and biosignatures: converging technologies, emerging partnerships; workshop summary. The National Academies Press: Washington, DC. Page 37-38. http://www.nap. edu/catalog.php?record_id=11947\#toc

DeKosky ST, Marek K (2003). Looking backward to move forward: early detection of neurodegenerative disorders. Science 302: 830-834.

Durst P, Schuff N, Crocq MA, Mokrani MC, Macher JP (1990). Noninvasive in vivo detection of a fluorinated neuroleptic in the human brain by $19 \mathrm{~F}$ nuclear magnetic resonance spectroscopy. Psychiatry Res 35: 107-114.

Erondu N, Gantz I, Musser B, Suryawanshi S, Mallick M, Abby C et al (2006). Neuropeptide Y5 receptor antagonism does not induce clinically meaningful weight loss in overweight and obese adults. Cell Metab 4: 275-282.

Fahn S, Oakes D, Shoulson I, Kieburtz K, Rudolph A, Lang A et al (2004). Levodopa and the progression of Parkinson's disease. N Engl J Med 351: 2498-2508.

Farde L, Nordstrom AL, Wiesel FA, Pauli S, Halldin C, Sedvall G (1992). Positron emission tomographic analysis of central D1 and D2 dopamine receptor occupancy in patients treated with classical neuroleptics and clozapine. Relation to extrapyramidal side effects. Arch Gen Psychiatry 49: 538-544.

Foa EB, Liebowitz MR, Kozak MJ, Davies S, Campeas R, Franklin ME et al (2005). Randomized, placebo-controlled trial of exposure and ritual prevention, clomipraminie, and their combination in the treatment of obsessive-compulsive disorder. Am J Psychiatry 162: 151-161.

Foster NL, Heidebrink JL, Clark CM, Jagust WJ, Arnold SE, Barbas NR et al (2007). FDG-PET improves accuracy in distinguishing frontotemporal dementia and Alzheimer's disease. Brain 130: 2616-2635.

Fox NC, Crum WR, Schaill RI, Stevens JM, Janssen JC, Rossor MN (2001). Imaging of onset and progression of Alzheimer's disease with voxel-compression mapping of serial magnetic resonance images. Lancet 358: 201-205.

Frank R, Hargreaves R (2003). Clinical biomarkers in drug discovery and development. Natl Rev Drug Discov 2: 566-580.

Fu CH, Williams SC, Cleare AJ, Brammer MJ, Walsh ND, Kim J et al (2004). Attenuation of the neural response to sad faces in major depression by antidepressant treatment: a prospective, event-related functional magnetic resonance imaging study. Arch Gen Psychiatry 61: 877-889.

Goff DC, Posever T, Herz L, Simmons J, Kletti N, Lapierre K et al (1998). An exploratory haloperidol-controlled dose-finding study of ziprasidone in hospitalized patients with schizophrenia or schizoaffective disorder. J Clin Psychopharmacol 18: 296-304.

Gomez-Mancilla B, Marrer E, Kehren J, Kinnunen A, Imbert G, Hillebrand R et al (2008). Central nervous system drug development: an integrative biomarker approach toward individualized medicine. NeuroRx 2: 683-695.

Gründer G, Carlsson A, Wong DF (2003). Mechanism of new antipsychotic medications: occupancy is not just antagonism. Arch Gen Psychiatry 60: 974-977.

Gründer G, Fellows C, Janouschek H, Veselinovic T, Boy C, Brocheler A et al (2008). The brain and plasma pharmacokinetics of aripiprazole in patients with schizophrenia: a [18F]fallypride PET study. Am J Psychiatry 165: 988-995.

Gründer G, Fuji Y, Offord SJ, Ravert HT, Dannals RF, Salzman JK et al (1997). Time course of 5-HT2a receptor occupancy in the human brain after a single dose of the putative antipsychotic drug MDL 100,907 measured by positron emission tomography. Neuropsychopharmacology 17: 175-185. 
Gründer G, Landvogt C, Vernaleken I, Buchholz HG, Hiemke C, Rosch F et al (2006). The striatal and extrastriatal D2/D3 receptor-binding profile of clozapine in patients with schizophrenia. Neuropsychopharmacology 31: 1027-1035.

Hargreaves RJ (2008). The role of molecular imaging in drug discovery and development. Clin Pharmacol Ther 83: 349-353.

Hariri AR, Drabant EM, Munoz KE, Kolachana BS, Mattay VS, Egan MF et al (2005). A susceptibility gene for affective disorders and the response of the human amygdala. Arch Gen Psychiatry 62: 146-152.

Hariri AR, Mattay VS, Tessitore A, Kolachana B, Fera F, Goldman D et al (2002). Serotonin transporter genetic variation and the response of the human amygdala. Science 297: 400-403.

Harmer CJ, Mackay CE, Reid CB, Cowen PJ, Goodwin GM (2006). Antidepressant drug treatment modifies the neural processing of nonconscious threat cues. Biol Psychiatry 59: 816-820.

Hermann P, Kotek J, Kubicek V, Lukes I (2008). Gadolinium(III) complexes as MRI contrast agents: ligand design and properties of the complexes. Dalton Trans 23: 3027-3047.

Hintersteiner M, Enz A, Frey P, Jaton AL, Kinzy W, Kneuer R et al (2005). In vivo detection of amyloid-beta deposits by near-infrared imaging using an oxazinederivative probe. Biotechnology 23: 577-583.

Ireland MD, Williams SCR (2006). Application of pharmacological MRI to preclinical drug discovery and development. In: Webb GA (ed). Chemistry and Materials Science, pp 855-877.

Jacobs LD, Beck RW, Simon JH, Kinkel RP, Brownscheidle CM, Murray TJ et al (2000). Intramuscular interferon beta-1a therapy initiated during a first demyelinating event in multiple sclerosis. N Engl J Med 343: 898-904.

Jenkins BG, Rosas HD, Chen YC, Makabe T, Myers R, MacDonald M et al (1998). $1 \mathrm{H}$ NMR spectroscopy studies of Huntington's disease: correlations with CAG repeat numbers. Neurology 50: 1357-1365.

Kapur S, Zipursky R, Jones C, Remington G, Houle S (2000). Relationship between dopamine $D(2)$ occupancy, clinical response, and side effects: a double-blind PET study of first-episode schizophrenia. Am J Psychiatry 157: 514-520.

Karson CN, Newton JE, Livingston R, Jolly JB, Cooper TB, Sprigg J et al (1993). Human brain fluoxetine concentrations. J Neuropsychiatry Clin Neurosci 5: 322-329.

Keefe RD, Bilder RM, Davis SM, Harvey PD, Palmer BW, Gold JM, et al, CATIE Investigators; Neurocognitive Working Group (2007). Neurocognitive effects of antipsychotic medications in patients with chronic schizophrenia in the CATIE Trial. Arch Gen Psychiatry 64: 633-657.

Keller M, Montgomery S, Ball W, Morrison M, Snavely D, Liu G et al (2006). Lack of efficacy of the substance $P$ (neurokinin 1 receptor) antagonist aprepitant in the treatment of major depressive disorder. Biol Psychiatry 33: 227-235.

Kessler RM, Ansari MS, Riccardi P, Li R, Jayathilake K, Dawant B et al (2006). Occupancy of striatal and extrastriatal dopamine D2 receptors by clozapine and quetiapine. Neuropsychopharmacology 31: 1991-2001.

Kikuchi T, Tottori K, Uwahodo Y, Hirose T, Miwa T, Oshiro Y et al (1995). 7-(4-[4-(2,3Dichlorophenyl)-1-piperazinyl]butyloxy)-3,4-dihydro-2(1H)quinolinone (OPC14597), a new putative antipsychotic drug with both presynaptic dopamine autoreceptor agonistic activity and postsynaptic D2 receptor antagonistic activity. $J$ Pharacol Exp Ther 274: 329-336.

Kramer MS, Cutler N, Feighner J, Shrivastava R, Carman J, Sramek JJ et al (1998). Distinct mechanism for antidepressant activity by blockade of central substance $\mathrm{P}$ receptors. Science 281: 1640-1645.

Kramer MS, Last B, Getson A, Reines SA (1997). The effects of a selective D4 dopamine receptor antagonist $(L-745,870)$ in acutely psychotic inpatients with schizophrenia. D4 Dopmaine Antagonist Group. Arch Gen Psychiatry 54: 567-572.

Lesch KP, Bengel D, Heils A, Sabol SZ, Greenberg BD, Petri S et al (1996). Association of anxiety-related traits with a polymorphism in the serotonin transporter gene regulatory region. Science 274: 1527-1531.

Logan J, Fowler JS, Volkow ND, Wolf AP, Dewey SL, Schlyer DJ et al (1990). Graphical anlysis of reversible radioligand binding from time-activity measurements applied to [N-[11C-methyl]-(-)-cocaine PET studies in human subjects. J Cereb Blood Flow Metab 10: 740-747.

Logan J, Wang GJ, Telang F, Fowler JS, Alexoff D, Zabroski J et al (2007). Imaging the norepinephrine transporter in humans with $(S, S)$-[11C]O-methyl reboxetine and PET: problems and progress. NuCl Med Biol 34: 667-679.

Lu ZR, Mohs AM, Zong Y, Feng Y (2006). Polydisulfide Gd(III) chelates as biodegradable macromolecular magnetic resonance imaging contrast agents. Int J Nanomedicine 1: 31-40.

Maeda J, Ji B, Irie T, Tomiyama T, Maruyama M, Okauchi T et al (2007). Longitudinal, quantitative assessment of amyloid, neuroinflammation, and antiamyloid treatment in a living mouse model of Alzheimer's disease enabled by positron emission tomography. J Neurosci 27: 10957-10958.
Mamo D, Graff A, Mizrahi R, Shammi CM, Romeyer F, Kapur S (2007). Differential effects of aripiprazole on $\mathrm{D}(2), 5-\mathrm{HT}(2)$, and 5-HT(1A) receptor occupancy in patients with schizophrenia: a triple tracer PET study. Am J Psychiatry 164: 1411-1417.

McCormick T, Martin K, Hehenberger M (2007). The evolving role of biomarkers: focusing on research from research to clinical practice. IBM Institute for Business Value: Somers, New York. http://www-935.ibm.com/services/us/gbs/bus/pdf/ g510-6640-00_biomarker.pdf

Meyer JH, Goulding VS, Wilson AA, Hussey D, Christensen BK, Houle S (2002). Bupropion occupancy of the dopamine transporter is low during clinical treatment. Psychopharmacology 163: 102-105.

Meyer JH, Wilson AA, Ginovart N, Goulding V, Hussey D, Hood K et al (2001). Occupancy of serotonin transporters by paroxetine and citalopram during treatment of depression: a [(11)C]DASB PET imaging study. Am J Psychiatry 158: 1843-1849.

Mills G (2008). The exploratory IND. J Nucl Med 49: 45N-47N

Need AB, McKinzie JH, Mitch $\mathrm{CH}$, Statnick $\mathrm{L}$, Phebus $\mathrm{L}$ (2007). In vivo rat brain opioid binding of LY255582 assessed with a novel method using LC/MS/ MS and the administration of three tracers simultaneously. Life Sci 81: 1389-1396.

Nyberg S, Eriksson B, Oxenstierna G, Halldin C, Farde L (1999). Suggested minimal effective dose of risperidone based on PET-measured D2 and 5-HT2A receptor occupancy in schizophrenic patients. Am J Psychiatry 156: 869-875.

Parkinson Study Group (2000a). A multicenter assessment of dopamine transporter imaging with DOPASCAN/SPECT in parkinsonism. Neurology 55: 1540-1547.

Parkinson Study Group (2000b). Pramipexole $v s$ levodopa as initial treatment for Parkinson disease: a randomized controlled trial. J Am Med Assoc 284: 1931-1938.

Parkinson Study Group (2002). Dopamine transporter brain imaging to assess the effects of pramipexole $v s$ levodopa on Parkinson disease progression. J Am Med Assoc 287: 1653-1661.

Patil ST, Zhang L, Martenyi F, Lowe SL, Jackson KA, Andreev BV et al (2007). Activation of mGlu2/3 receptors as a new approach to treat schizophrenia: a randomized phase 2 clinical trial. Nat Med 13: 1102-1107.

Plenge P, Stensgaard A, Jensen HV, Thomsen C, Mellerup ET, Henriksen O (1994). 24-hour lithium concentration in human brain studied by $\mathrm{Li}-7$ magnetic resonance spectroscopy. Biol Psychiatry 36: 511-516.

Rowe CC, NG S, Ackermann U, Gong SJ, Savage G, Cowie TF et al (2007). Imaging beta-amyloid burden in aging and dementia. Neurology 68: 1718-1725.

Seeman P, Lee T, Chau-Wong M, Wong K (1976). Antipsychotic drug doses and neuroleptic/dopamine receptors. Nature 261: 717-719.

Seneca N, Gulyas B, Varrone A, Schou M, Airaksinen A, Tauscher J et al (2006). Atomoxetine occupies the norepinephrine transporter in a dose-dependent fashion: a PET study in nonhuman primate brain using (S,S)-[18F]FmeNER-D2. Psychopharmacology 188: 119-127.

Shinotoh H, Iyo M, Yamada T, Suzuki K, Itoh T, Fukuda H et al (1989). Detection of benzodiazepine receptor occupancy in the human brain by positron emission tomography. Psychopharmacology 99: 202-207.

Staner $L$ (2006). Surrogate outcomes in neurology, psychiatry, and psychopharmacology. Dialog Clin Neurosci 8: 345-352.

Suhara T, Takano A, Sudo Y, Ichmiya T, Inoue M, Yasuno F et al (2003). High levels of serotonin transporter occupancy with low-dose clomipramine in comparative occupancy study with fluvoxamine using positron emission tomography. Arch Gen Psychiatry 60: 386-391.

Tauscher J, Jones C, Remington G, Zipursky BB, Kapur S (2002). Significant dissociation of brain and plasma kinetics with antipsychotics. Mol Psychiatry 7: 317-321.

Vernaleken I, Fellows C, Janouschek H, Bröcheler A, Veselinivic T, Landvogt C et al (2008). Striatal and extrastriatal $D_{2 / 3}$ receptor binding properties of ziprasidone: a PET studies with $\left[{ }^{18} \mathrm{~F}\right]$ fallypride and $\left[{ }^{11} \mathrm{C}\right]$ raclopride. J Clin Psychopharmacol, in press

Villemagne VL, Rothman R, Yokoi F, Rick KC, Matecka D, Dannals RF et al (1999a). Doses of GBR12909 which suppress cocaine self-administration in non-human primates substantially occupy dopamine transporters as measured by [11C]WIN 35,428 PET scans. Synapse 32: 44-50.

Villemagne VL, Wong DF, Yokoi F, Stephane M, Rick KC, Matecka D et al (1999b). GBR12909 attenuates amphetamine-induced striatal dopamine release as measured by [11C]raclopride continuous infusion PET scans. Synapse 33: 268-273.

Wagner HN, Rosas HD, Dannals RF, Wong DF (1983). Imaging dopamine receptors in the human brain by positron tomography. Science 188: 119-127.

Whone AL, Watts RL, StoessI AJ, Davis M, Reske S, Nahmias C et al (2003). Slower progression of Parkinson's disease with ropinirole versus levodopa: the REALPET study. Ann Neurol 54: 93-101. 
Wise RG, Tracey I (2006). The role of fMRI in drug discovery. J Magn Reson Imaging 23: 862-876.

Wolkin A, Barouche F, Wolfe AP, Rotrosen J, Fowler JS, Schiue CY et al (1989). Dopamine blockade and clinical response: evidence for two biological subgroups of schizophrenia. Am J Psychiatry 146: 905-908.

Wong DF, Potter WZ, Brasic J (2002). Proof of concept: functional models for drug development in humans. In: Charney D, Coyle J, Davis K,
Nemeroff (eds). Neuropsychopharmacology: The Fifth Generation of Progress. Lippincott Williams \& Wilkins: Baltimore, MD. pp 457-473.

Yokoi F, Gründer G, Biziere K, Stephane M, Dogan AS, Dannals RF et al (2002). Dopamine $D(2)$ and $D(3)$ receptor occupancy in normal humans treated with the antipsychotic drug arpiprazole (OPC 14597). A study using position emission tomography. Neuropsychopharmacology 27: 248-259. 